\title{
Three-dimensional hydrodynamic and water quality model for TMDL development of Lake Fuxian, China
}

\author{
Lei Zhao ${ }^{1,4}$, Xiaoling Zhang ${ }^{2}$, Yong $\mathrm{Liu}^{2}$, Bin $\mathrm{He}^{4}$, \\ Xiang Zhu ${ }^{4}$, Rui Zou ${ }^{3, *}$, Yuanguan $\mathrm{Zhu}^{1}$ \\ 1. Research Center for Eco-Environmental Sciences, Chinese Academy of Sciences, Beijing 100085, China. \\ E-mail: zlzny@yies.org.cn \\ 2. College of Environmental Science and Engineering, Key Laboratory of Water and Sediment Sciences (MOE), \\ Peking University, Beijing 100871, China \\ 3. Tetra Tech, Inc. 10306 Eaton Place, Ste 340, Fairfax, VA 22030, USA \\ 4. Institute for Environmental Sciences, Kunming 650034, China
}

Received 11 October 2011; revised 07 March 2012; accepted 09 March 2012

\begin{abstract}
Lake Fuxian is the largest deep freshwater lake in China. Although its average water quality meets Class I of the China National Water Quality Standard (CNWQS), i.e., GB3838-2002, monitoring data indicate that the water quality approaches the Class II threshold in some areas. Thus it is urgent to reduce the watershed load through the total maximum daily load (TMDL) program. A three-dimensional hydrodynamic and water quality model was developed for Lake Fuxian, simulating flow circulation and pollutant fate and transport. The model development process consists of several steps, including grid generation, initial and boundary condition configurations, and model calibration processes. The model accurately reproduced the observed water surface elevation, spatiotemporal variations in temperature, and total nitrogen (TN), total phosphorus (TP), and chemical oxygen demand (COD) concentrations, suggesting a reasonable numerical representation of the prototype system for further TMDL analyses. The TMDL was calculated using two interpretations of the water quality standards for Class I of the CNWQS based on the maximum instantaneous surface and annual average surface water concentrations. Analysis of the first scenario indicated that the TN, TP and COD loads should be reduced by $66 \%, 68 \%$ and $57 \%$, respectively. Water quality was the highest priority; however, local economic development and cost feasibility for load reduction can pose significant issues. In the second interpretation, the model results showed that, under the existing conditions, the average water quality meets the Class I standard and therefore load reduction is unnecessary. Future studies are needed to conduct risk and cost assessments for realistic decision-making.
\end{abstract}

Key words: hydrodynamic and water quality model; Lake Fuxian; water quality prediction; total maximum daily load DOI: $10.1016 /$ S1001-0742(11)60967-4

\section{Introduction}

Load reduction is the fundamental way to meet lake water quality goals. Decision making on load reduction requires a scientifically sound method and analytical framework, and water quality modeling (WQM) provides such a basis for determining water environmental capacity and supporting load reduction calculations. Watershed management is affected greatly by model selection (Borsuk et al., 2002; Effler et al., 2002; Depinto et al., 2004; Fang et al., 2007; Liu et al., 2008; Ke et al., 2009; Shi et al., 2010; Tao, 2010). Usually, after pollutants enter lakes, there is relatively strong vertical differentiation, and shortterm high nutrient concentrations directly stimulate algae outbreaks. Therefore, when developing a water quality model, these factors should be considered to create proper spatiotemporal resolutions and the environmental capacity,

\footnotetext{
* Corresponding author. E-mail: rz5q@yahoo.com
}

or total maximum daily load (TMDL) of the system should be studied. Accurate, reliable water-quality models help to analyze lake pollution status, and provide quantitative information for decision-making and environmental management. Moreover, it has been identified that reliable mathematical modeling forms a core component of intelligent watershed management (Zou et al., 2011).

Lake Fuxian is the largest deep freshwater lake in China. Its average water quality meets Class I of the China National Water Quality Standard (CNWQS), i.e., GB3838-2002; however, monitoring data indicate that the water quality violates Class I and approaches the threshold of Class II in some areas of the lake. Moreover, Lake Fuxian has experienced one algal bloom. Due to its deep lake characteristics, studies have focused on field monitoring or remote sensing (Li et al., 2003; Zhang and Zhang, 2008). There are no physical or chemical data available for the middle-lower layer. In addition, the previous water 
quality model for Lake Fuxian ignored spatial differences in lake water quality and inter-annual dynamics, and could not be used for a refined TMDL (Ma et al., 1997). The Environmental Fluid Dynamics Code (EFDC) is numerical modeling software for surface water that has been applied to simulate reservoirs, bays, lakes, wetlands, and estuaries, such as Lake Wuliangsuhai in Inner Mongolia, Lake Dianchi, Lake Kunchenghu, the Three Gorges Reservoir, the Niagara River, the Neuse River estuary, and Lake Mead, a deep lake (Wool et al., 2003; Park et al., 2005; Zou et al., 2006; Wan and Li, 2007; Lian, 2008; Cao et al., 2009; Li, 2009; Franceschini and Tsai, 2010; Li et al., 2010, 2011; Xia et al., 2011).

To provide scientifically sound decision support for protecting the water quality in Lake Fuxian, a TMDL program needs to be developed to guide future watershed management and load reduction. The primary purpose of this study was to develop a computational platform to quantify the cause-and-effect relationship between watershed loading and in-lake concentration of Lake Fuxian, and calculate the TMDL for Lake Fuxian. To fulfill this purpose, we developed an EFDC-based three-dimensional (3D) hydrodynamic and water quality model for Lake Fuxian. It was developed to simulate the fate and transport of total nitrogen (TN), total phosphorus (TP), and chemical oxygen demand (COD) in the lake and to accurately reproduce the spatiotemporal distribution of the observed pollutants in the lake. The TMDL was then determined based on the model scenario analysis under two CNWQS interpretations.

\section{Modeling framework}

\subsection{Study area}

Lake Fuxian is a fault dissolution lake in Yuxi, Yunnan Province, China (Fig. 1). It has a normal water elevation of $1722.5 \mathrm{~m}$, average lake depth of $95.2 \mathrm{~m}$, and maximum depth of $158.9 \mathrm{~m}$. The lake area is 21.66 million $\mathrm{m}^{2}$ and its volume is 20.62 billion $\mathrm{m}^{3}$. Lake Fuxian accounts for $9.16 \%$ of the total lake freshwater in China. The main tributaries into Lake Fuxian are the Luju River on the south coast, the Wuche River on the east coast, the Jianshan River on the west coast, and the Daicun, Dongda, Maliao, Shapen, and Liangwang Rivers and the Yaoni Ditch on the north coast. These rivers have become severely polluted by human activities including phosphate mining and processing in the watershed, which directly affects the lake water quality. Studies have shown that phytoplankton numbers have increased 2.6 times and the chlorophyll $a$ concentration by a factor of 3 . Furthermore, transparency has been reduced nearly by half and the integrated nutritional index (INI) has increased sharply, indicating a risk of eutrophication for Lake Fuxian ( $\mathrm{Li}$ et al., 2003). Developing a WQM-based TMDL program for Lake Fuxian is important, as it could determine a quantitative response relationship between the internal water quality and pollution loads of external sources to provide scientific support for watershed management.

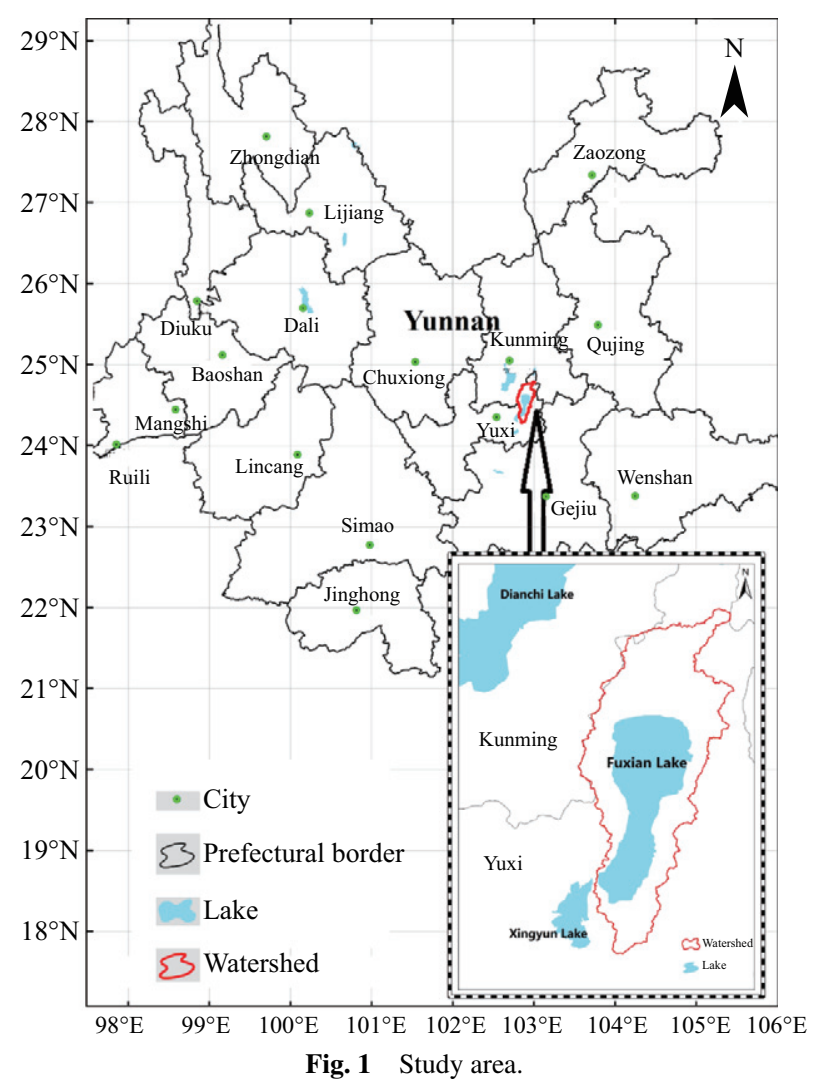

\subsection{EFDC model}

EFDC is one of the most widely applied advanced modeling frameworks for simulating hydrodynamics, water quality, eutrophication, and dynamic changes and interactions in sediment transportation. The EFDC hydrodynamic governing equations include momentum, continuity, and transport equations related to salinity and temperature represented by Eqs. (1)-(8) (Hamrick, 1992, 1996; Park et al., 1995; Zou et al., 2008):

$$
\begin{aligned}
& \partial_{t}(m H u)+\partial_{x}\left(m_{y} H u u\right)+\partial_{y}\left(m_{x} H v u\right)+\partial_{z}(m w u)- \\
& \left(m f+v \partial_{x} m_{y}-u \partial_{y} m_{x}\right) H v= \\
& \quad-m_{y} H \partial_{x}(g \zeta+p)-m_{y}\left(\partial_{x} h-z \partial_{x} H\right) \partial_{z} p+ \\
& \partial_{z}\left(m H^{-1} A_{v} \partial_{z} u\right)+Q_{u} \\
& \partial_{t}(m H v)+\partial_{x}\left(m_{y} H u v\right)+\partial_{y}\left(m_{x} H v v\right)+\partial_{z}(m w v)- \\
& \left(m f+v \partial_{x} m_{y}-u \partial_{y} m_{x}\right) H u= \\
& \quad-m_{x} H \partial_{y}(g \zeta+p)-m_{x}\left(\partial_{x} h-z \partial_{y} H\right) \partial_{z} p+ \\
& \partial_{z}\left(m H^{-1} A_{v} \partial_{z} v\right)+Q_{v} \\
& \partial_{z} p=-g H\left(\rho-\rho_{0}\right) \rho_{0}^{-1}=-g H b \\
& \partial_{t}(m \zeta)+\partial_{x}\left(m_{y} H u\right)+\partial_{y}\left(m_{x} H v\right)+\partial_{z}(m w)=0 \\
& \partial_{t}(m \zeta)+\partial_{t}\left(m_{y} H \int_{0}^{1} u \mathrm{~d} z\right)+\partial_{y}\left(m_{x} H \int_{0}^{1} v \mathrm{~d} z\right)=0 \\
& \rho=\rho(p, S, T) \\
& \partial_{t}(m H S)+\partial_{x}\left(m_{y} H u S\right)+\partial_{y}\left(m_{x} H v S\right)+\partial_{z}(m w S)= \\
& \quad \partial_{z}\left(m H^{-1} A_{b} \partial_{z} S\right)+Q_{S} \\
& \partial_{t}(m H T)+\partial_{x}\left(m_{y} H u T\right)+\partial_{y}\left(m_{x} H v T\right)+\partial_{z}(m w T)= \\
& \quad \partial_{z}\left(m H^{-1} A_{b} \partial_{z} T\right)+Q_{T}
\end{aligned}
$$


where, $u$ and $v$ are the horizontal velocity components in the curvilinear, orthogonal coordinates $x$ and $y$, respectively; $m_{x}$ and $m_{y}$ are the square roots of the diagonal components of the metric tensor; $m=m_{x} m_{y}$ is the Jacobian or square root of the metric tensor determinant. $H$ is the sum of the depth below the free surface displacement relative to the undisturbed physical vertical coordinate origin, $z^{*}=0 . p$ is the physical pressure in excess of the reference density hydrostatic pressure, $\rho_{0} g H(1-z)$, divided by the reference density, $\rho_{0}$. The density, $\rho$, is in general a function of temperature, $T$, and salinity $S$, while $b$ is the buoyancy which is defined in equation as the normalized deviation of density from the reference value (Hamrick, 1992). In the momentum equations $f$ is the Coriolis parameter, $A_{\mathrm{v}}$ is the vertical turbulent or eddy viscosity, and $Q_{u}$ and $Q_{v}$ are momentum source-sink terms. In the transport equations for salinity and temperature, $Q_{s}$ and $Q_{T}$ are source and sink terms, while $A_{b}$ is the vertical turbulent diffusivity.

The governing mass-balance equation for the water quality state variables can be expressed as Eq. (9) (Park et al., 1995):

$$
\begin{aligned}
& \frac{\partial C}{\partial t}+\frac{\partial(u C)}{\partial x}+\frac{\partial(v C)}{\partial y}+\frac{\partial(w C)}{\partial z}= \\
& \frac{\partial}{\partial x}\left(K_{x} \frac{\partial C}{\partial x}\right)+\frac{\partial}{\partial y}\left(K_{y} \frac{\partial C}{\partial y}\right)+\frac{\partial}{\partial z}\left(K_{z} \frac{\partial C}{\partial z}\right)
\end{aligned}
$$

$\frac{\partial C}{\partial t}=S_{\mathrm{c}}$

where, $C$ is the concentration of a water quality state variable; $u, v$, and $w$ are the velocity components in the curvilinear, sigma, $X$-, $Y$-, and $Z$-axis, respectively; $K_{x}, K_{y}$, and $K_{z}$ are the turbulent diffusivities in the $X-, Y$-, and $Z$ axis, respectively; $S_{\mathrm{c}}$ represents the internal and external sources and sinks per unit volume; and $H$ is the water column depth (Park et al., 1995).

\subsection{EFDC development for Lake Fuxian}

EFDC is a hydrodynamic water quality model that can be applied to any specific surface water, including lakes and rivers. It can simulate functions by numerically characterizing physical, chemical, and ecological processes. Developing a 3D hydrodynamic water quality model for Lake Fuxian is a multi-step process that includes grid generation, configuration of initial and boundary conditions, and model calibration and application.

\subsubsection{Grid generation}

The model used the curved grid method to describe the shoreline of Lake Fuxian, which matched the lake border shape by dividing fewer networks and improving computational efficiency before ensuring spatial accuracy. The horizontal cross-section curve was generated for a discrete water body and then each lattice depth was specified using topographic information. Horizontally, Lake Fuxian was divided into 323 orthogonal curvilinear grids and the grids were divided into 50 layers to represent the vertical water depth features according to the sigma coordinates (Fig. 2).

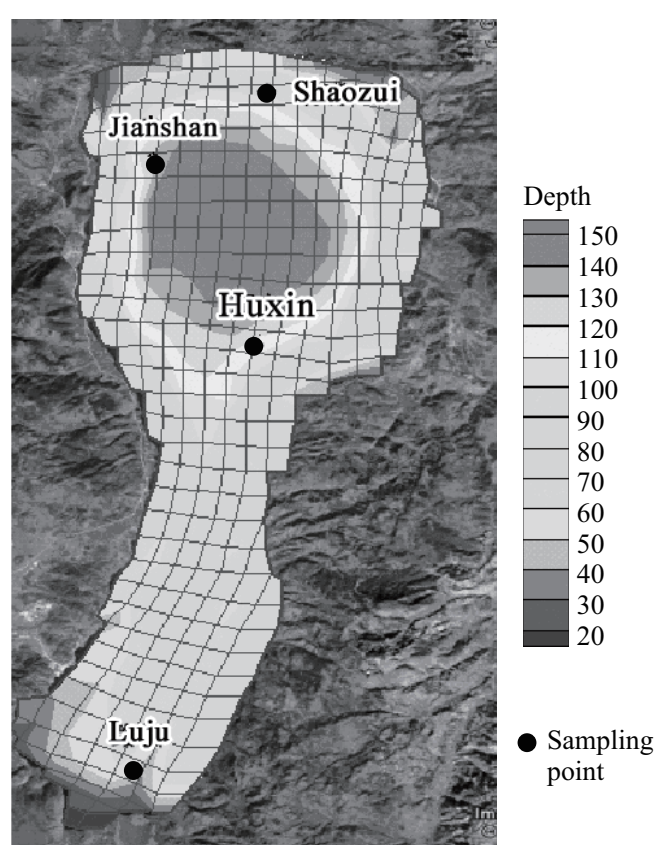

Fig. 2 Grid generation and monitoring stations for the hydrodynamic and water quality model of Lake Fuxian.

In total, the lake was divided into 16,150 units to solve the control equations.

\subsubsection{Initial conditions}

The initial conditions were used as the starting point for the model simulation. The period simulated was from January to December, 2009. A water height of $1723.28 \mathrm{~m}$, observed on 1 January 2009, was set as the initial elevation. The initial temperature was set as $13.5^{\circ} \mathrm{C}$ based on a value observed in early January. The three velocity vectors were initialized as $0.0 \mathrm{~m} / \mathrm{sec}$ by conventional hydrodynamics. Initial water quality data from 6 January 2009 were used, with initial TP, TN and COD concentrations of 0.005 , 0.171 and $0.98 \mathrm{mg} / \mathrm{L}$, respectively.

\subsubsection{Boundary conditions}

The model boundary conditions were the external driving forces applied to the model system. The horizontal boundary conditions included tributary flow into the lake and the associated temperature and water quality components of the tributaries. The surface boundary conditions were expressed by time-related meteorological conditions, including solar radiation, wind speed and direction, air temperature, air pressure, relative humidity and cloud cover. In the Lake Fuxian model, the horizontal boundary conditions, flow and pollutant concentrations were based on data from the main tributaries during January to December, 2009 and accounted for the reverse valuation adjustment under the condition of watershed model calibration data shortage. The spatial expression of the horizontal boundary conditions was based on measured geographic coordinates. The atmospheric boundary data driving the fluid model were processed into a format compatible with the EFDC to configure the boundary conditions, based on hourly weather data from meteorological stations in Chengjiang County. 


\section{Results and discussion}

\subsection{Hydrodynamic simulation and calibration}

Model calibration is the core process in water quality model development. When a water quality model is used as the analytical framework for TMDL development, the relative validity and reliability of the resultant TMDL is generally dependent on the calibration of the model prediction against observed data. The calibration process estimates parameter patterns to describe and reproduce the conditions in the water column. The first step for the Lake Fuxian hydrodynamic water quality model was a hydrodynamic and flow balance simulation. The hydrodynamic model was developed and calibrated before running the water quality model to save computation time in the calibration phase. The model calculation time step was $30 \mathrm{sec}$. The simulation period covered the entire year of 2009 from January 1st through December 31st. The flow simulation results indicated that under the combined effects of inflow, outflow, and wind shear stress, the water circulation patterns of Lake Fuxian changed with time and location (Fig. 3). The time-dependent flow pattern implies that the same amount of nutrients can have different impacts on the in-lake water quality after entering the lake during different periods of time due to the change in the flow pattern. Therefore, it is desired to develop a dynamic
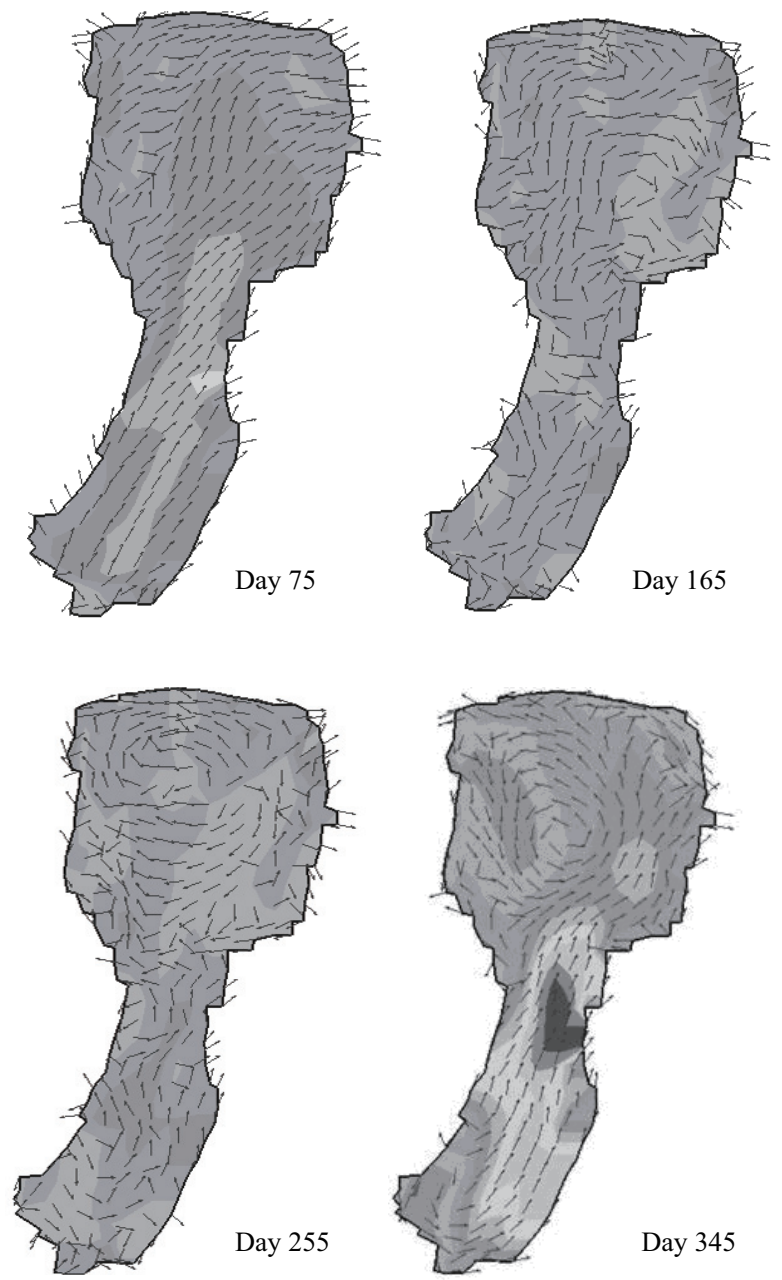

Fig. 3 Simulated time-variable flow field in Lake Fuxian.

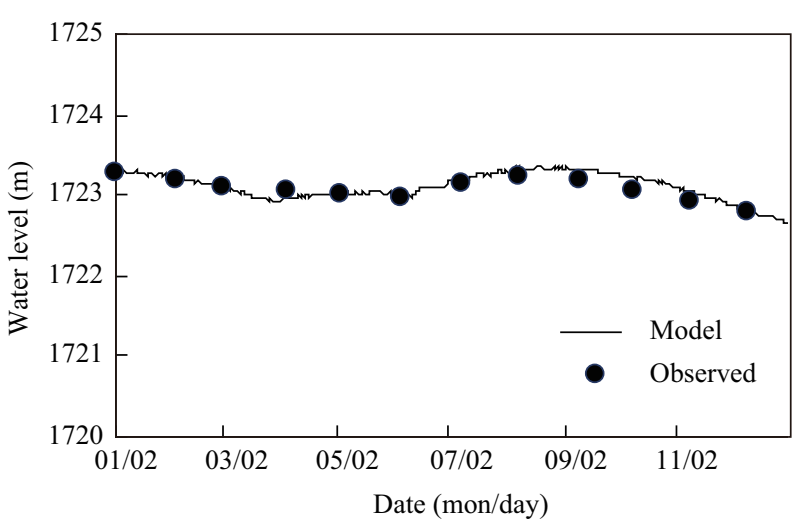

Fig. 4 Comparison of simulated and observed water surface elevation.

model to represent such temporal variability for decision support .

As shown in Fig. 4, the simulated water level results matched the observed trend very well, indicating that the water balance in the hydrodynamic model was well maintained. Typically, for freshwater lake dynamic models, temperature is one of the most important calibration parameters, because it reflects physical processes and heat balance in fluid dynamics. No calibration against flow field data was conducted due to the lack of data. Furthermore, for lake hydrodynamic models, it is no longer a standard practice to calibrate against the flow field due to the fact that in a lake the circulation velocity is generally very slow. The measured velocity field tends to be non-representative and might be subjected to significant errors. Therefore, for freshwater lakes, temperature calibration is reported in the literature (Zou et al., 2008) to be the major calibration parameter. In addition, most water dynamic processes are associated with temperature. The temperature calibration was based on the observed surface and deep monitoring results from four monitoring points: Shaozui, Jianshan, Huxin, and Luju (Fig. 2). The deep-water temperature monitors were approximately $20 \mathrm{~m}$ below the water surface. Figure 5 presents the model results at $6 \mathrm{hr}$ intervals at Huxin and Jianshan. The model accurately simulated the seasonal trends and overall observed temperature differences spatiotemporally and represented the natural physical conditions of the lake formed by the hydro- and thermodynamic coupling process. The other monitoring sites had similar conditions as Huxin and Jianshan.

\subsection{Water quality simulation and calibration}

The purpose of the water quality calibration was to customize the EFDC water quality model to the local lake conditions by evaluating model parameters, and to accurately reflect the water quality response to pollutants entering the lake. Only when the model is well calibrated to reproduce the observed water quality pattern in the lake, can the TMDL calculation using the model be considered to be relatively reliable and accurate. The calibration was implemented via an iterative process where the model parameters were fine-tuned until the model reproduced the observed trend for multiple water qualities. The simulation period was 1 January through 31 December 2009. The model calibration parameters were the first-order decay 

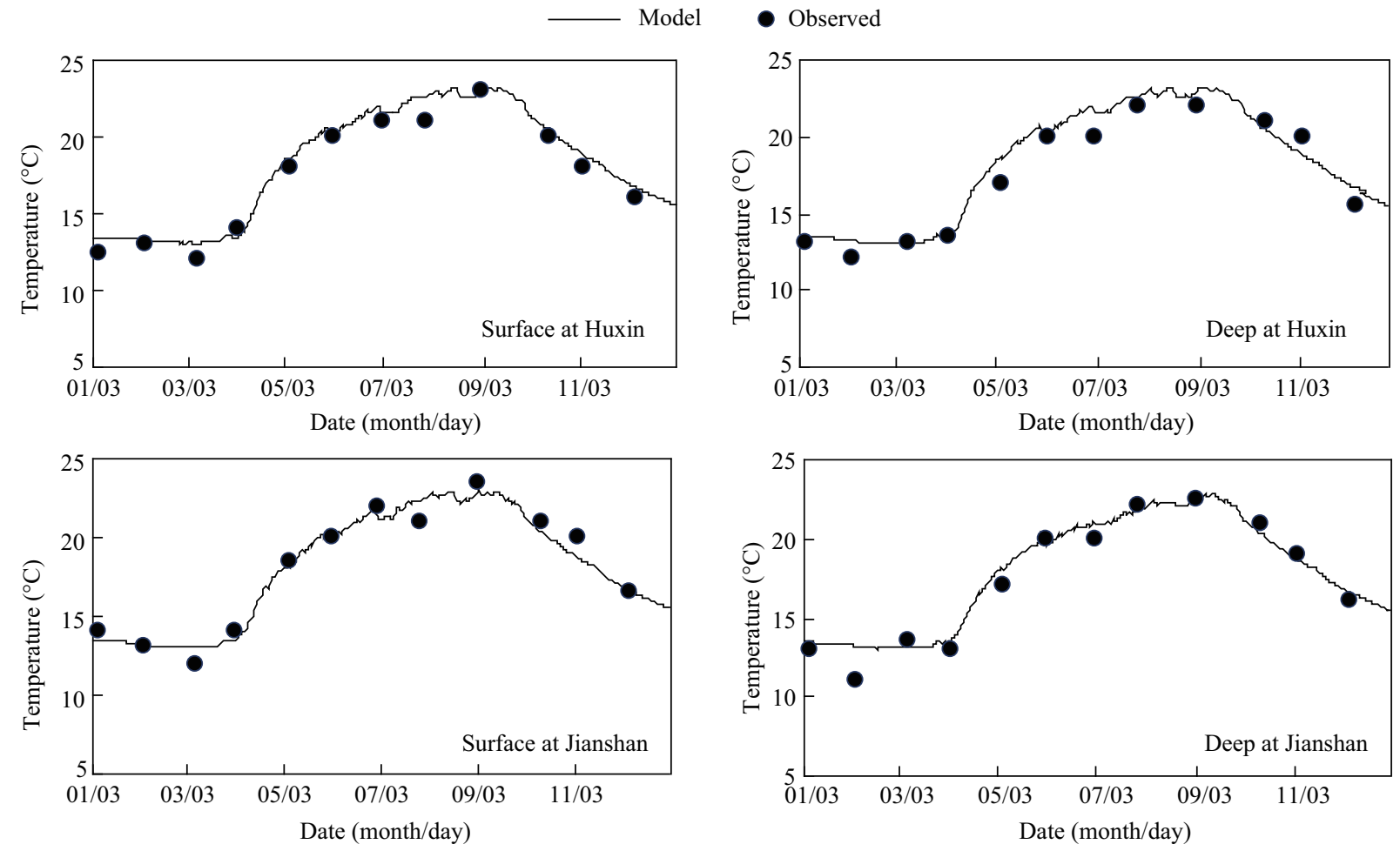

Fig. 5 Comparison of simulated and observed water temperature.

rate. The sedimentation rate of the water quality state variables are listed in Table 1. The model calibration ran for about 20 iterations until the spatiotemporal water quality distributions of the simulated and observed data matched. Figure 6 compares the simulation results for TN, TP and COD with the experimental data. The results indicated that when a relatively large pulse of pollutants entered the lake, the pollutant concentrations at the monitoring sites near the entrance of inflowing rivers rapidly increased instantaneously and decreased abruptly after peaking. However, water quality at monitoring points far from the input changed smoothly and gradually. Accurately reproducing the spatiotemporal characteristics demonstrated that the $3 \mathrm{D}$ hydrodynamic water quality model realized the transport and transformation value expression for internal pollutants in Lake Fuxian; this provided the foundation for computing the environmental capacity as an analyzable platform in the next step.

\subsection{Discussion}

Since Lake Fuxian is deep and oligotrophic, the nutrient load at the bottom has a weak influence over the entire lake, particularly the upper euphotic zone, over the short term. Therefore, the internal load of the bottom was ig-

Table 1 Calibrated model parameters for Lake Fuxian

\begin{tabular}{lll}
\hline Parameter & $\begin{array}{l}\text { Decay rate } \\
\text { (per day) }\end{array}$ & $\begin{array}{l}\text { Settling rate } \\
\text { (m/day) }\end{array}$ \\
\hline COD & 0.002 & 0.01 \\
TP & 0.005 & 0.01 \\
TN & 0.005 & 0.01 \\
\hline
\end{tabular}

COD: chemical oxygen demand; TP: total phosphorus; TN: total nitrogen. nored when exploring the vertical distribution of pollutant concentrations after a specific pollutant load pulse entered Lake Fuxian. Figure 7 shows the simulation results on day 170, one day after Lake Fuxian received a watershed pollutant load pulse. As water depth increased, the TP, $\mathrm{TN}$, and COD concentrations decreased, as the load pulse of watershed pollutants mainly had a rapid impact on the surface, whereas it took a relatively long time to diffuse into the deep water.

The model results show that there exists relatively strong vertical stratification of nutrient concentrations after a specific loading pulse event. Since only the nutrients in the euphotic layer would directly stimulate algal outbreaks, therefore, it is not reasonable to calculate TMDL, or environmental carrying capacity, based on the entire lake. If the entire lake is considered as a whole to calculate the environmental capacity or TMDL as was done before, the calculation would tend to over-estimate the amount of pollutant than can be assimilated by the lake water, hence result in an overly high TMDL that would be unsafe for the protection of the lake water quality. Therefore, the water quality model for the environmental capacity calculation of Lake Fuxian must be three-dimensional to express pollutant transportation and transformation processes and differentiation both horizontally and vertically. In addition, the pollutant concentration decline from the surface to the bottom is a result of runoff after abundant rains. During the dry season, high concentrations are likely to form in the benthic layer due to a long mixing time and endogenous effects. A more in-depth analysis of these phenomena depends on a quantitatively comprehensive system that links endogenous, exogenous, and algal dynamics through data collection and refined model research. 


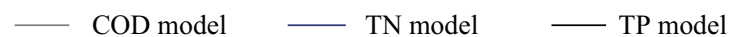

- TN observed $\quad \Delta \quad$ TP observed $\quad$ COD observed
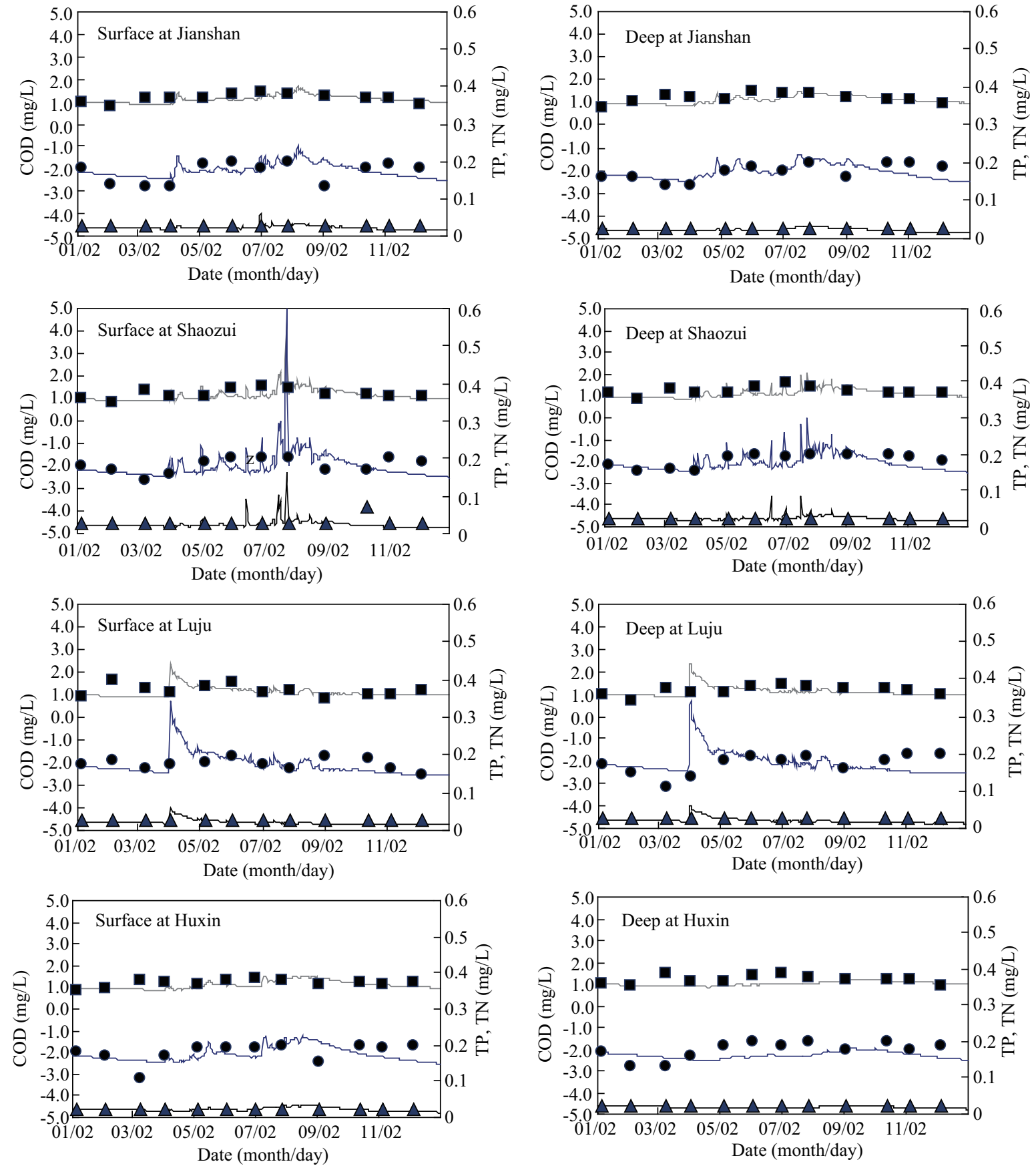

Fig. 6 Simulated vs. observed water quality concentrations. TP is expanded five times.

\section{Scenario analysis results}

After calibration, the hydrodynamic water quality model can be used to analyze different water quality standard scenarios for Lake Fuxian, providing basic information to determine the watershed TMDL. To calculate the environmental capacity, the implemented environmental quality standards for surface water should be defined clearly. For example, although in the CNWQS the TP concentration must be $\leqslant 0.01 \mathrm{mg} / \mathrm{L}$ to meet the Class I standard, interpreting this standard to match the capacity calculation has the problem of suiting the measures to local conditions. For
Lake Fuxian, the most stringent interpretation is the maximum instantaneous surface concentration, which requires that at any place or time, the inner surface TP concentration must be $<0.01 \mathrm{mg} / \mathrm{L}$. Another interpretation is the annual average concentration across the surface water, which requires the annual average surface TP concentration in Lake Fuxian to be $\leqslant 0.01 \mathrm{mg} / \mathrm{L}$. In addition, there are some intermediate interpretations, for example, allowing 5\% or $10 \%$ of measurements to be in excess of the allowed rate. These alternatives were not within the scope of the present study, but should be researched in more depth to help decision makers. 


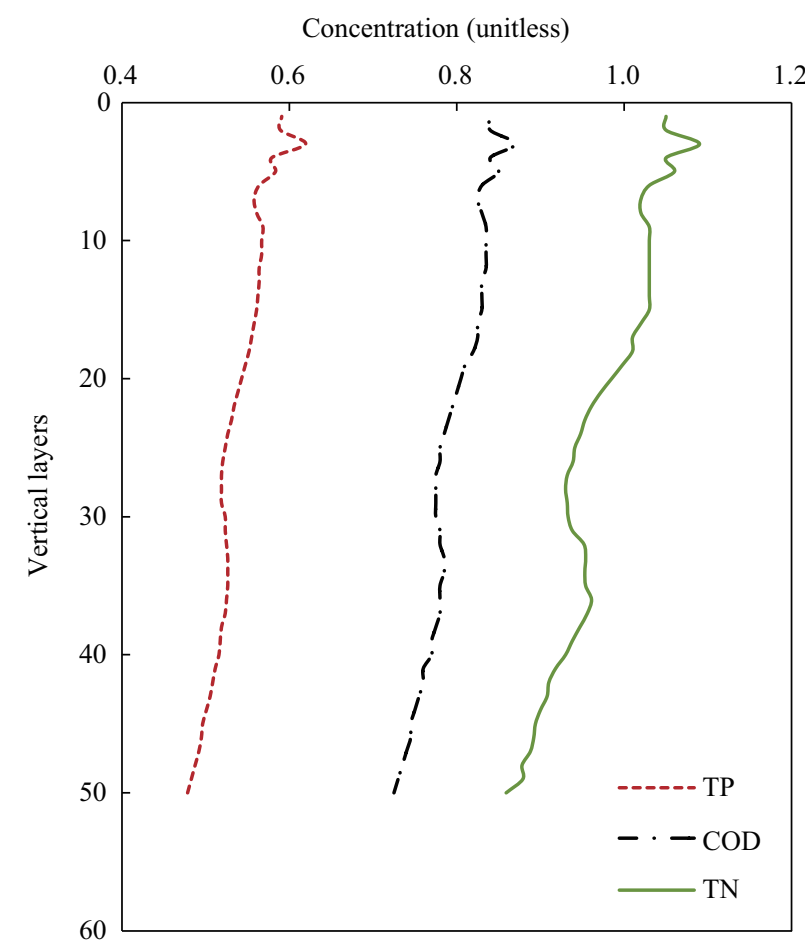

Fig. 7 Simulated vertical profile of nutrient concentrations at Huxin station. All the concentrations are converted to comparable scales, i.e., TP and TN concentrations are scaled up by 150 times and 5 times, respectively, to make TP, TN and COD comparable in the same scales. The vertical layers are ordered from surface to bottom.

\subsection{Scenario One: a standard interpretation based on the maximum instantaneous surface concentration}

Scenario One was based on the most stringent interpretation of the environmental quality standards. It used the calibrated model in 2009 as the baseline for the watershed load reduction and ran a continuous simulation for five years. The 5-year simulation period was necessary to allow the model reach a quasi-steady state for evaluating the long term impact of loading scenarios (Cao et al., 2009). During the simulation, all parameters were the same as in the calibration model and meteorological conditions remained unchanged. The simulated temperature and water quality at the end of the first year were used as the initial conditions in the second year. The final results were used to determine if water quality standards were achieved.

After 15 iterations, the model completed the corresponding TMDL calculation with a cumulative computation time (Intel Core Duo $2.66 \mathrm{GHz}$ computer) of 32 days. Loading was determined based on flow and watershed inflow concentrations. There were no point sources in the 2009 boundary conditions because all point sources were placed at the inflow point and only the load entering the lake mattered for the TMDL calculation. The existing loading in 2009 was calculated as 1759, 90, and 14063 tons/yr of TN, TP, and COD, respectively. According to the standards in Scenario One, the pollutant loads into Lake Fuxian exceeded the capacity requirements and TN, TP, and COD loading must be reduced by $66 \%, 68 \%$, and $57 \%$, respectively. Using the 2009 hydrological conditions as the load calculation conditions, the environmental capacity of Lake Fuxian under this interpretation was 598, 29 and 6050 tons/yr of TN, TP and COD, respectively.

Under Scenario One, the local administrations should control watershed pollution to prevent load increases. Moreover, engineering and management measures should be implemented to significantly reduce the loads and ensure that the surface water meets the Class I standard. This scenario is the best plan for protecting Lake Fuxian, to control extreme pollutant concentrations under the Class I standard, and reduce the risk of algal blooms so that the water quality remains high and sustainable.

\subsection{Scenario Two: standard interpretation based on annual average concentration across the surface water}

Scenario Two was based on the annual average concentration across the surface water, under which the TN, TP and COD concentrations met the Class I standard. Therefore, watershed loading and human activities of all the pollutants could increase. To determine the environmental capacity under this interpretation, after 11 iterations, the model completed the corresponding calculation process with a cumulative computation time of 24 days. The results indicated that the TN, TP and COD concentrations could increase by $41 \%, 230 \%$ and $75 \%$, respectively. The environmental capacities of TN, TP, and COD were 2480, 297 and 24600 tons/yr, respectively, based on the hydrological conditions in 2009.

While Scenario One would place lake water quality as the highest priority, economic development and cost feasibility would be major issues. Compared with Scenario One, Scenario Two corresponds to a much less stringent management strategy. It ignores lake ecosystem harm from short-term peak concentrations and has a low watershed management target, which could result in water quality deterioration. The corresponding environmental capacity under Scenario Two was calculated, but it is not recommended. Therefore, watershed management efforts should consider the environmental capacity from Scenario One as the ultimate goal and a series of compromises between Scenarios One and Two should be studied to provide a scientific basis for adaptive watershed management.

The present analysis demonstrated that environmental capacity is a relative value. For low-risk policies concerning Lake Fuxian water quality, the environmental capacity corresponding to Scenario One should be used; conversely, if decision-makers can tolerate some risks, the capacities derived from Scenario Two could be used.

\section{Conclusions}

(1) An EFDC-based 3D hydrodynamic water quality model was developed for Lake Fuxian. The model accurately reproduced the natural physical conditions of the lake formed by hydrodynamic and thermodynamic coupling through water level correction and temperature calibration. (2) The model reasonably simulated the complex and dynamic physical and chemical processes in Lake Fuxian and accurately predicted the spatiotemporal water quality concentrations. (3) For specific water bodies, environment 
capacity, or TMDL, is a relative value. It is closely related to environmental standard interpretations and decisionmaking risk levels. If the interpretation is conservative and strict, the TMDL places water quality as a priority; conversely, the less stringent TMDL is associated with a relatively large risk of water quality deterioration. (4) Lake Fuxian is a simple ecosystem that is vulnerable to pollutant impacts. Two scenarios were identified as benchmarks for the total capacity control. Scenario One used the maximum instantaneous surface concentration as the end point to evaluate compliance, while Scenario Two was based on the annual average surface water concentration. Based on Scenario One, the TN, TP, and COD loadings should be reduced by $66 \%, 68 \%$ and $57 \%$, respectively, under the existing conditions, which would prioritize lake water quality over further economic development. On the other hand, Scenario Two indicated that if only the annual average concentration is of concern, then further increase in watershed-loading is still possible without violating the water quality standard. Apparently, the so-called TMDL for a lake is not a single value but dependent on the interpretation of the water quality target. The two scenarios provide a basis for bounding the future development and conservation activities in the watershed; however, further in-depth studies should be conducted in the future to quantify the relationships between watershed load, lake nutrient concentration, and algal response, hence more accurately guide future watershed management based on the actual water quality threat-algal bloom risk.

\section{Acknowledgments}

This work was supported by the National Natural Science Foundation of China (No. 41101180) and the China National Water Pollution Control Program (No. 2010ZX07102-006).

\section{References}

Borsuk M E, Stow C A, Reckhow K H, 2002. Predicting the frequency of water quality standard violations: A probabilistic approach for TMDL development. Environmental Science $\mathcal{E}$ Technology, 36(10): 2109-2115.

Cao J J, Li R J, Qin Y, 2009. Simulation of water quality of shallow lakes in cities: the example of Kuncheng Lake. Water Resources Protection, 25(4): 12-15.

Depinto J V, Freedman P L, Dilks D M, Larson W M, 2004. Models quantify the total maximum daily load process. Journal of Environmental Engineering-ASCE, 130(6): 703713.

Effler S W, O'Donnell S M, Matthews D A, Matthews C M, O'Donnell D M, Auer M T et al., 2002. Limnological and loading information and a phosphorus total maximum daily load (TMDL) analysis for Onondaga Lake. Lake and Reservoir Management, 18(2): 87-108.

Fang X B, Zhang J Y, Chen W, Xu X Y, Chen Y X, 2007. Assimilative capacity of the Qiantang River watershed based on a QUAL2K model. Acta Scientiae Circumstantiae, 27(8): 1402-1407.

Franceschini S, Tsai C W, 2010. Assessment of uncertainty sources in water quality modeling in the Niagara River. Advances in Water Resources, 33(4): 493-503.

Hamrick J M, 1992. A three-dimensional environmental fluid dynamics computer code: Theoretical and computational aspects. Special paper 317 , the College of William and Mary, Virginia Institute of Marine Science, Williamsburg, VA.

Hamrick J M, 1996. User's Manual for the Environmental Fluid Dynamics Computer Code. Special Report No. 331 in Applied Marine Science and Ocean Engineering. Department of Physical Sciences, School of Marine Science, Virginia Institute of Marine Science, The College of William and Mary, Gloucester Point, VA.

Ke Q, Zhao J, Wang S P, Zheng W D, Yin D Q, 2009. Application of total maximum daily load (TMDL) in control of agricultural non-point source pollution and its developmental trend. Journal of Ecology and Rural Environment, 25(1): $85-91$.

Li X, 2009. Study on dynamic numerical simulation of water quality for Wuliangsuhai Lake in Inner Mongolia. Inner Mongolia: Inner Mongolia Agricultural University.

Li Y P, Acharya K, Chen D, Stone M, 2010. Modeling water ages and thermal structure of Lake Mead under changing water levels. Lake and Reservoir Management, 26(4): 258-272.

Li Y X, Liu H, Lu Y, Wang L, 2003. Preliminary studies on eutrophication in Fuxian Lake. Journal of Lake Science, 15(3): 285-288.

Liu Y, Yang P J, Hu C, Guo H C, 2008. Water quality modeling for load reduction under uncertainty: A Bayesian approach. Water Research, 42(13): 3305-3314.

Ma W S, Zhang X M, Li Y X, 1997. Study of water quality model for deep lakes and its application to lake Fuxian. Yunnan Environmental Science, 16(3): 37-39.

Park K, Jung H S, Kim H S, Ahm S M, 2005. Three-dimensional hydrodynamic-eutrophication model (HEM-3D): application to Kwang-Yang Bay, Korea. Marine Environmental Research, 60(2): 171-193.

Park K, Kuo A, Shen J, Hamrick J, 1995. (rev. by Tetra Tech, Inc. 2000). A Three-dimensional HydrodynamicEutrophication Model (HEM-3D): Description of Water Quality and Sediment Process Submodels (EFDC Water Quality Model). Special Report No. 327 in Applied Marine Science and Ocean Engineering.

Shi T C, Wang F E, Fang X B, 2010. Regional management strategy integrated with WASP model on water quality for river-network plain located in Huzhou District, Taihu Lake Basin. Acta Scientiae Circumstantiae, 30(3): 631-640.

Tao Y, 2010. Water environmental management and prediction of Shenzhou bay based on a EFDC model. Central University for Nationalities, Beijing.

Wan J B, Li Y Y, 2007. Progress in the research of lake water quality model. Resources and Environment in the Yangtze Basin, 16(6): 805-809.

Wang J N, 2008. Research on dispatching mode improving water quality of three gorges reservoir in non-flood season. Master Thesis. Tianjin University, Tianjin.

Wool T A, Davie S R, Rodriguez H N, 2003. Development of three-dimensional hydrodynamic and water quality models to support total maximum daily load decision process for the Neuse River Estuary, North Carolina. Journal of Water Resources Planning and Management-ASCE, 129(4): 295306.

Xia M, Craig P M, Wallen C M, Stoddard A, Mandrup-Poulsen J, Peng M C et al., 2011. Numerical simulation of salinity 
and dissolved oxygen at Perdido Bay and Adjacent Coastal Ocean. Journal of Coastal Research, 27(1): 73-86.

Zhang J, Zhang Z, 2008. A study of remote sensing investigation for water quality pollution of the Fuxian and Xingyun Lakes in Yunnan Province using MODIS data. Hydrogeology $\mathcal{E}$ Engineering Geology, 35(5): 92-96.

Zou R, Carter S, Shoemaker L, Parker A, Henry T, 2006. Integrated hydrodynamic and water quality modeling system to support nutrient total maximum daily load development for
Wissahickon Creek, Pennsylvania. Journal of Environmental Engineering-ASCE, 132(4): 555-566.

Zou R, Bai S, Parker A, 2008. Hydrodynamic and eutrophication modeling for a tidal marsh impacted estuarine system using EFDC. Coastal and Estuary Modeling, 561-589.

Zou R, Liu Y, Yan X P, Guo H C, 2011. Key components and modeling framework for intelligent watershed management (IWM). Acta Scientiarum Naturalium Universitatis Pekinensis, 47(5): 868-874. 